\title{
Challenges Facing Building Information Modelling in Construction Industry in Sudan
}

\author{
Ahmed Ibrahim \\ ahmedeltigani08@gmail.com \\ Faculty of Engineering, University of Khartoum, Khartoum, Sudan
}

Amged O. Abdelatif

Amged.Abdelatif@uofk.edu

Department of Civil Engineering, Faculty of Engineering, University of Khartoum, Khartoum, Sudan

\begin{abstract}
Building Information Modelling (BIM) is a valuable and promising approach in Architecture, Engineering and Construction (AEC) industry, which is gradually gaining acceptance by owners, architects, engineers, and contractors as an innovative process of generating and managing building data during its lifecycle. This paper aims to mark the main challenges that are faced by the adoption of BIM and the current BIM maturity level in Sudan. The most challenging issue was found to be the absence of clients demand to implement BIM in their projects. According to this study, the maturity level in AEC in Sudan was found to be Level 1.
\end{abstract}

Keywords: BIM; Construction industry; Implementation; Challenges; Maturity level

\section{INTRODUCTION}

The construction industry is one of the most information dependent sectors and relies heavily on traditional means of communications, which needs effective methods for gathering and utilizing performance information on industry, companies, and individual project levels.

Since many years Construction Industry (CI) in Sudan is developing slowly and facing many problems and obstacles, such as: shortage of materials, fluctuation of construction materials' prices, inaccurate estimation of the time, defects during the process of construction, cost overrun, too much pressure on project stakeholders, etc. Recently, many technologies that would improve the construction process were developed, latest and the most popular among them, is Building Information Modelling (BIM), (Khidir $\mathrm{M} \mathrm{O}, 2016)$.

The adoption of technology in Sudan is moving very slowly, it is affected by economic factors and sanctions. This affects the construction process and adoption of BIM, which is a promising technology lead to transform the construction industry. Therefore, BIM is a working method that requires a new mind set, and mind set change is essential to successful BIM adoption (Mohamed M B, 2015).

Thus, the aim of this study is to identify the main challenges and difficulties facing the implementation and adoption of BIM and to evaluate the status of BIM adoption in Sudan. 


\section{CHALlengeS}

A survey was conducted to gain a better understanding of the background and facts concerning BIM implementation and the challenges that face the organizations to adopt BIM in Sudan.

The questionnaire was broken down into three main sections. The first section focused on general questions related to the type of firm, personal experiences and position of respondents in their organization. The second section focused on the degree of awareness of BIM, and how respondents understand the concept. The third section concentrated on barriers and challenges to BIM and suggested ways to deal with those barriers. The numbers of respondents are 50 in the respective three sections.

Figure 1 demonstrates the main challenges affecting the spread of using BIM suggested by respondents, of which $40 \%$ results show that the clients do not demand their work being done by using BIM, while $18 \%$ of respondents claim that the most affecting factor is lack of support from managers. $16 \%$ is the cost of BIM adoption, $14 \%$, the lack of BIM training and 10\%, the lack of BIM experts in the industry, while only $2 \%$ claim that the main reason is the lack of knowledge among engineers.



Figure 1: The challenges of using BIM

\section{BIM MATURITY LEVEL}

Figure 2 shows the ranges of maturity levels of Building Information Modelling (Eastman et al., 2009). The BIM maturity is categorized in four levels:

\subsection{Level 0 BIM}

Unmanaged Computer Aided Design (CAD) including 2D drawings, and text with the paper-based or electronic exchange of information but without common standards and processes. Essentially this is a digital drawing board.

\subsection{Level 1 BIM}

Managed CAD, with the increasing introduction of spatial coordination, standardized structures and formats as it moves towards Level 2 BIM. This may include 2D information and 3D information such as visualizations or concept development models. Level 1 can be described as 'Lonely BIM' as models are not shared between project team members.

\subsection{Level 2 BIM}

Managed 3D environment with data attached, but created in separate discipline-based 
models. These separate models are assembled to form a federated model but do not lose their identity or integrity. Data may include construction sequencing (4D) and cost (5D) information. This is sometimes referred to as 'pBIM' (proprietary BIM).

\subsection{Level 3 BIM}

A single collaborative, online, project model with construction sequencing (4D) cost (5D) and project life-cycle information (6D). This is sometimes referred to as 'iBIM' (integrated BIM) and is intended to deliver better business outcomes.

\subsection{Level 4 BIM}

Level 4 introduces the concepts of improved social outcomes and well-being.

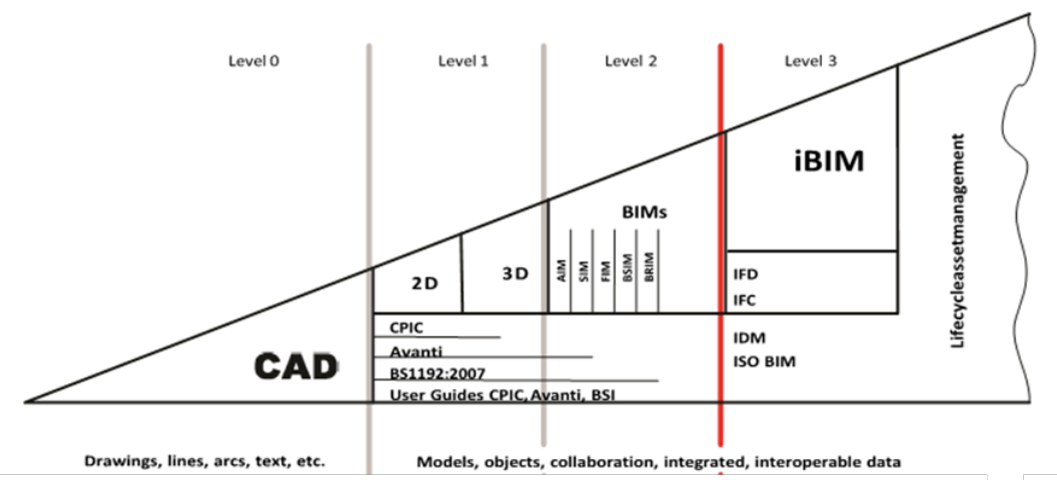

Figure 2: BIM maturity levels (Eastman et al., 2009)

In order to assess the maturity level, interviews with major companies have been conducted in order to investigate the issue of implementing BIM in Sudan, as follows:

- What is the degree of awareness of BIM in Sudan?

- Which level are Sudanese firms in maturity level of BIM?

- How to adopt best practices of BIM in Sudan?

As shown in Figure 3, 80\% interviewees see Sudanese companies at BIM maturity Level 1, the remaining $20 \%$ mainly at maturity Level 0 .



Figure 3: Sudanese construction industry maturity levels of BIM 


\section{CONCLUSION}

The importance of BIM adoption is becoming increasingly recognized by the construction industry all over the world, which has been facing barriers and challenges to increase productivity, efficiency, quality. The paper's aim was to identify the main challenges facing the adoption of BIM in Sudan and the findings indicate that there are numbers of challenges regarding the adoption and implementation. The main challenge was found to be the absence of client demands in the construction industry in Sudan. The paper also assesses the status of BIM in Sudan by using the BIM maturity level gauge. The results revealed that the Sudanese organizations have clear evidence of BIM use in level 1 maturity level.

\section{REFERENCES}

Eastman, C., Tiecholz, P., Sacks, R. \& Liston, K. (2008). BIM Handbook. New Jersey: John Wiley \& Sons.

Khidir, M. O. (2016). Implementation and potential benefits of Building Information Modeling (BIM) in Sudan construction industry (Sudan University of Science and Technology).

Mohamed, M. B. I. (2015). A study of project delay in Sudan construction industry (Partial thesis of Master's degree, Universiti Tunku Abdul Rahman, Malaysia). 